\title{
Endoscopic pneumatic dilatation and peroral endoscopic myotomy in dilated megaesophagus
}

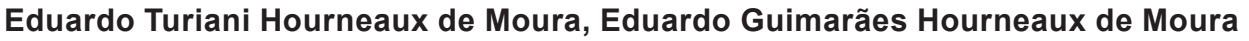 \\ Gastrointestinal Endoscopy Unit, Hospital das Clinicas, University of São Paulo Medical School, São Paulo, SP 01246-903, Brazil.
}

Correspondence to: Dr. Eduardo Turiani Hourneaux de Moura, Gastrointestinal Endoscopy Unit, Hospital das Clinicas, University of São Paulo Medical School, 255, São Paulo, SP 01246-903, Brazil. E-mail: duduthmoura@gmail.com

How to cite this article: de Moura ETH, de Moura EGH. Endoscopic pneumatic dilatation and peroral endoscopic myotomy in dilated megaesophagus. Mini-invasive Surg 2017;1:148-52.

Article history:
Received: 20 Jul 2017
First Decision: 1 Aug 2017
Revised: 11 Sep 2017
Accepted: 28 Sep 2017
Published: 28 Dec 2017
Key words:
Chagas disease,
megaesophagus,
sigmoid-shaped esophagus,
pneumatic dilatation,
peroral endoscopic myotomy,
endoscopic gastrointestinal
surgery procedures

\begin{abstract}
Achalasia is a primary esophageal disorderth variable causes, with an incidence between 0.03 to $1 / 100,000$ people, and prevalence of approximately $10 / 100,000$, with no difference between gender. It is more frequent in South and Central America, where Chagas disease is endemic. There are several methods to treat achalasia including endoscopic and surgical procedures, however, all of these methods are palliative. This article discusses 2 different endoscopic methods to treat advanced megaesophagus in Chagas disease, pneumatic balloon dilatation (PBD), and peroral endoscopic myotomy (POEM). Although varying between studies, PBD has an average symptom relief in $93 \%$ of patients in 6 months and $44 \%$ in 6 years. Some risk factors for failure of PBD are: younger age, male gender, a wider esophagus, poor emptying on posttreatment barium esophagogram and Eckardt scale $<3$ before the treatment. Despite relatively short-term follow-up of an average of 3 years, POEM has excellent results. The clinical success achieved in $98 \%$ with the Eckardt score decreased from 6.9 preoperatively to 0.77 . Regarding sigmoid-shaped esophagus, only a few papers have been published on POEM. The largest population was 32 patients with a follow-up of 2 years. There was an efficacy of $96 \%$, with the Eckardt scale decreasing from 7.8 to 1.4 . In conclusion, PBD, is still widely used mainly due to its availability, especially in patients with a higher surgical risk and in patients who already had a Heller myotomy who persist or develop dysphagia. POEM has already demonstrated excellent results, but it requires advanced technical skills and Long-term results and randomized clinical trials are needed to validate the use of POEM in routine clinical practice.
\end{abstract}

\section{INTRODUCTION}

Achalasia is a primary esophageal disorder of variable causes, with an incidence between 0.03 to $1 / 100,000$ people, and a prevalence of approximately 10/100,000, with no difference between gender ${ }^{[1-4]}$.
It is more frequent in South and Central America, where Chagas disease is endemic. In addition to infectious etiology, other causes of achalasia are idiopathic, autoimmune, or drug-related ${ }^{[5]}$.

Chagas disease is an incurable disease where there

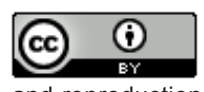

This is an open access article licensed under the terms of Creative Commons Attribution 4.0 International License (https://creativecommons.org/licenses/by/4.0/), which permits unrestricted use, distribution, and reproduction in any medium, as long as the original author is credited and the new creations are licensed under the identical terms.

For reprints contact: service@oaepublish.com

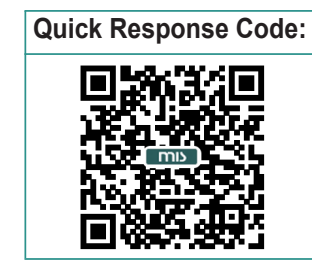


is total or partial destruction of the intramural motor plexus (Auerbach plexus and Meissner plexus), leading to esophageal aperistalsis and relaxation of the lower esophageal sphincter (LES).

With this underlying pathology, the patients present with progressive dysphagia, retrosternal pain, regurgitation, and weight loss ${ }^{[6]}$.

There are several treatments for this pathology, including medication, surgical and endoscopic treatments. All are palliative because the disease has an unknown pathogenesis with an evolutionary characteristic.

In patients with chagasic disease, the esophagus can dilate to a large caliber. In this circumstance, a well-renowned Brazilian doctor, Ferreira-Santos ${ }^{[7]}$, developed a radiological classification defined by the transverse diameter of the esophagus image contrasted in the antero-posterior incidence, and by the stasis time, that helps with the orientation of the treatment to be used.

Grade I - Moderate dilatation, up to $4 \mathrm{~cm}$ of transverse diameter. Small stasis at 5 min.

Grade II - Dilation up to $7 \mathrm{~cm}$ of transverse diameter. Stasis at $30 \mathrm{~min}$.

Grade III - Dilation up to $10 \mathrm{~cm}$ of transverse diameter with sigmoid-shaped esophagus. Persistence of stasis after $30 \mathrm{~min}$.

Grade IV - Dilation greater than $10 \mathrm{~cm}$ of transverse diameter with deviation of the longitudinal axis of the esophagus.

The sigmoid-shaped esophagus (Grade III and Grade IV) is considered to be the advanced stage of achalasia, in which the esophageal lumen is significantly dilated, swerved, and rotated. Up to $10 \%$ of all patients with long-standing achalasia (defined as more than 10 years after first diagnosis) developed a sigmoid-shaped esophagus and/or megaesophagus. Endoscopic treatment of advanced achalasia with sigmoid type esophagus is still controversial. Most of the people recommend esophagectomy, mainly in Grade IV, while others recommend myotomy as the first step. Successful treatment of sigmoid-shaped esophagus with laparoscopic Heller myotomy has been demonstrated by several studies ${ }^{[8-10]}$.

A Brazilian group led by Crema et al. ${ }^{[11]}$, published a paper that assists physicians in managing patients with sigmoid-shaped esophagus Grade III. They analyzed the radiologic and manometric findings of 43 patients suffering from chagasic megaesophagus with positive tests for Chagas disease. There was a significant reduction in the high pressure levels of the body of the esophagus related to the stage of the disease: stage $\mathrm{I} / \mathrm{II}-42.9 \mathrm{mmHg}$, stage III - $23.6 \mathrm{mmHg}$, and stage IV $-15.6 \mathrm{mmHg}$. It was observed that five $(35.7 \%)$ stage III patients had high pressure levels below $20 \mathrm{mmHg}$ presenting with advanced megaesophagus and underwent a subtotal esophagectomy following esophagogastroplasty instead of cardiomyotomy with anti-reflux valve. The manometric study in stage III patients with chagasic megaesophagus was considered helpful to indicate which surgical procedure would be best for these patients.

Several methods to evaluate the efficacy of the procedure, such as high resolution or conventional manometry to measure the LES pressure and the body motility, upper endoscopy, and emptying timed barium esophagogram (to measure the width and the height of barium column) pre and post-treatment should be done.

In addition, some scales can also be used to evaluate the efficacy of the treatment, such as: the Eckardt et al. ${ }^{[12]}$ scale [Table 1], visual analog scale ${ }^{[13]}$ and quality life SF 36 questionnaire ${ }^{[14]}$.

In regards to endoscopic treatments, there are three types available: injection of botulinum toxin in the LES, pneumatic balloon dilatation (PBD) and peroral endoscopic myotomy (POEM).

The use of botulinum toxin is not common outside the USA and Europe due to its high cost and also because the durability is very low, lower than the PBD. Some authors defend that esophageal botox injections seems particularly appropriate for high-risk patients, but should not be considered a completely safe procedure, with complications rates up to $7.9 \%$ in the largest case series available ${ }^{[15]}$.

In this chapter we will discuss the most available and used two types of endoscopic treatment for achalasia: PBD and POEM.

Table 1: Grading system for evaluating clinical symptoms of achalasia, Eckardt et al. ${ }^{[12]}$

\begin{tabular}{lcccc}
\hline Score & $\begin{array}{c}\text { Weight } \\
\text { loss }\end{array}$ & Dysphagia & $\begin{array}{c}\text { Retroesternal } \\
\text { pain }\end{array}$ & Regurgitation \\
\hline 0 & None & None & None & None \\
1 & $<5 \mathrm{~kg}$ & Occasional & Occasional & Occasional \\
2 & $8-10 \mathrm{~kg}$ & Daily & Daily & Daily \\
3 & $>10 \mathrm{~kg}$ & Each meal & Each meal & Each meal \\
\hline
\end{tabular}




\section{PNEUMATIC BALLOON DILTATION}

PBD uses a pneumatic balloon for low compliance, which is a balloon with minimal deformity and uniform distension throughout its extension. This design promotes the rupture of the muscular fibers of the LES, diminishing its hypertonia. Consequently, this facilitates passage of the alimentary bolus from the esophagus to the gastric chamber ${ }^{[16]}$.

The first balloon built was by Hurst in 1898. Different manufactured models of balloons were developed by Witzel in 1970, the first balloon was used with the gastroscope. Physical characteristics of the balloons, such as the high complacency, defined as high nonuniform balloon deformity, could increase the risk of perforation in the healthy area of the esophagus because the balloon reached its greatest distension diameter in the area of the minimal resistance.

With the advent of pneumatic balloons with low complacency, balloons with minimal deformity and uniform distension throughout its length, the risk of complications, particularly perforation, was minimized. Currently, the low-compliant balloon is used, which has different sizes (30, 35 and $40 \mathrm{~mm}$ ) and are much larger than the standard through-the-scope balloons. As a result, the pressure generated by PBD is significantly more effective in fracturing the muscularis propria of the LES.

The dilatation can be done under direct endoscopic view, in which the balloon is placed at the height of the LES and the insufflation was performed under endoscopic vision until the maximum balloon measurement or until the patient begins to feel pain. It can also be done under radiological vision, in which the balloon is placed at the height of the LES. Under continuous radioscopy, the balloon is inflated to its maximum extent, visualizing the formation of a radiological waist in the balloon. Some groups interrupt the inflation after radiological waist loss, while other groups inflate the balloon to its maximum size.

The treatment of achalasia over the years has been carried out mainly through PBD due to its greater availability. However, PBD, although an effective method, has variable durability in different studies. It is also associated with a theoretical higher risk of gastroesophageal reflux disease occurrence between $15-35 \%$ of patients due to the total rupture of the circular and longitudinal muscular layers of the LES ${ }^{[16]}$. However, this modality presents a low risk for major complications and deaths compared to surgery. It is currently the most effective non-surgical option for the treatment of achalasia.

Initial dilatation is performed using a $30-\mathrm{mm}$ balloon and an objective evaluation of the symptoms after 4-6 weeks. For patients who continue to remain symptomatic, dilatation with next-sized balloon should be made. This serial pneumatic dilation approach has been shown to have excellent success rates. Although varying between studies, with relief of symptoms in up to $93 \%$ of patients in 6 months to $44 \%$ in 6 years ${ }^{[17,18]}$. Additionally, the risk of perforation may be lower with the serial pneumatic dilation approach.

Some risk factors for failure PBD are: younger age, male sex, wider esophagus, poor emptying on post-treatment timed barium esophagogram and Eckardt et al. ${ }^{[12]}$ scale < 3 before treatment.

Balloon dilatation of the cardia is not indicated for advanced megaesophagus, since the reduction of symptoms is less compared to the non-advanced form and its durability is less than 6 months. Although, a paper published from Pakistan ${ }^{[19]}$ showed that 9 patients with dilated megaesophagus (Grade $>$ II) with transverse diameter $>7 \mathrm{~cm}$, were treated using a $35 \mathrm{~mm}$ balloon without complications and with symptomatic improvement at 12-month follow-up.

\section{PERORALENDOSCOPICCARDIOMYOTOMY}

POEM introduced by Ortega et al. ${ }^{[20]}$ in 1980 and later standardized by Inoue et al. ${ }^{[21]}$ in 2010, is a new type of endoscopic treatment, which has been widespread in the past seven years.

This procedure performed with the upper digestive endoscopy is an esophageal and gastric myotomy with submucosal layer dissection under general anesthesia.

A cushion is formed in the submucosal layer of the esophagus, followed by a $2-\mathrm{cm}$ incision in the mucosa to access the submucosal layer through the anterior or posterior wall. The creation of a submucosal tunnel is carried out to the esophagogastric junction, entering about 2-4 cm into the stomach.

Next, the myotomy of the gastric part is performed, followed by myotomy of the esophageal muscular layer. Some groups perform the total myotomy of the circular and longitudinal layers of the esophagus, while others perform only the myotomy of the circular layer. It is important to vary the extent of the esophageal myotomy from 6 to $10 \mathrm{~cm}$ towards the middle esophagus to the gastroesophageal junction (GEJ). Finally, the incision of the mucosal layer is closed with the placement of endoclips or by endoscopic suture. 
The first publication on POEM was by Inoue et al. ${ }^{[21]}$ in 2010 with 17 patients. The mean myotomy was $8 \mathrm{~cm}, 6$ $\mathrm{cm}$ from the esophageal part and $2 \mathrm{~cm}$ from the gastric portion, with a significant decrease in the pressure of the lower esophageal sphincter (52.4 to $19.9 \mathrm{~mm}$ ). There was no recurrence of dysphagia with a short follow-up of 5 months.

Initial published experience in humans ${ }^{[22]}$ with nonsigmoid megaesophagus is more encouraging despite a relatively short-term follow-up (3 years). The largest series case ${ }^{[22]}$ of 500 patients had Eckardt et al. ${ }^{[12]}$ score decreasing from $6.0 \pm 3.0$ to $1.0 \pm 2.0$ and lower esophageal sphincter (LES) pressures from $25.4 \pm 17.1$ to $13.4 \pm 5.9 \mathrm{mmHg}$ with a mean follow-up of 3 years post-POEM. Gastroesophageal reflux was seen in $16.8 \%$ of patients at two months and $21.3 \%$ at 3 -year follow-up.

The most recent meta-analysis ${ }^{[23]}$ involved 2,373 patients with a clinical success of $98 \%$ after the procedure. On one hand, the mean Eckardt et al. ${ }^{[12]}$ score decreased from $6.9 \pm 0.15$ pre-operatively to $1.0 \pm 0.08$ within 12 months of treatment. In addition, there were significant decreases in the average lower esophageal sphincter pressure, integrated relaxation pressure and the average heights of the barium column following a timed barium esophagogram after the procedure. On the other hand, a mean followup of 8 months post-procedure shows symptomatic gastroesophageal reflux in $8.5 \%$ and esophagitis on esophagogastroduodenoscopy in $13 \%$.

Only a few papers ${ }^{[24]}$ have been published about POEM for sigmoid-shaped esophagus. The dilated and tortuous esophagus lumen may make the endoscopic dissection and separation of tissue more challenging and time consuming. The largest population was published by Hu et al. ${ }^{[25]}$ with 32 patients and follow-up of 2 years with an efficacy of $96 \%$. The Eckardt et al. ${ }^{[12]}$ scale decreased from 7.8 to 1.4 and the LES pressure from 37.9 to $12.9 \mathrm{mmHg}$. No serious complications were observed. However, the most common complication was clinical reflux with an average of $25.8 \%$ of the patients.

Recent studies have shown that POEM results in better improvement of dysphagia and reduction of LES pressure and lower complication rates compared to PBD.

However, recent studies have shown that gastroesophageal reflux is more common in POEM, ranging from $15 \%$ to $35 \%$ in some studies, and myotomy in the posterior wall is more susceptible to reflux. Moreover, the formation of adhesions between the submucosal layer and the longitudinal musculature after POEM may make it challenging if surgical revision is necessary for recurrence or persistent dysphagia after POEM.

\section{CLINICAL PRACTICE}

At Clinicas Hospital University of São Paulo, one of the most experienced centers that treat patients with achalasia caused by Chagas disease, the endoscopic treatment through the pneumatic dilatation of the cardia or POEM is indicated in degrees I and II based on Ferreira-Santos classification.

In grade III, the option for POEM is questionable and in grade IV, dilation is indicated only with the intention to preparing the patient (providing greater nutritional intake) for surgical treatment.

From the surgical point of view, Heller's cardiomyotomy is indicated in degrees I, II and III, whereas in grade IV esophagectomy is the preferred technique.

At present, both gastroenterologists and surgeons do not know which modality of treatment is better to patients with degrees II, comparing POEM, PBD and Heller's cardiomyotomy and I.

At our institution, the first line treatment to patients degree I is PBD. In degrees II and III, patients up to 70-year-old without high-risk comorbidities are referred to POEM or Heller and in degree IV esophagectomy as the preferred technique. However, if the patient does not have surgical conditions, PBD is performed to provide greater nutritional intake and to relieve symptoms. The botulinum toxin is not currently available at our institution.

\section{CONCLUSION}

In conclusion, in spite of promising results, POEM requires significant qualifications, and because it is a recent procedure, lacks reproducibility. Long-term results and randomized clinical trials before validating the use of POEM in routine clinical practice for the treatment of esophageal achalasia.

In relation to balloon dilatation of the cardia, even with variable durability mainly in advanced megaesophagus, it is still widely used in older patients, with a higher surgical risk, and in many cases in patients already submitted to Heller's surgery who persist or develop dysphagia. 


\section{DECLARATIONS}

\section{Authors' contributions}

Literature review: E.T.H. de Moura

Wrote, revised and approved the manuscript and the final version: E.T.H. de Moura, E.G.H. de Moura

\section{Financial support and sponsorship \\ None.}

\section{Conflicts of interest}

There are no conflicts of interest.

\section{Patient consent}

Not applicable.

\section{Ethics approval}

Not applicable.

\section{REFERENCES}

1. Fei L, Rossetti G, Moccia F, Cimmino M, Guerriero L, Romano G, Pascotto B, Orlando F. Definition, incidence and etiology: what's new in the 21st century? Ann Ital Chir 2013;84:489-94.

2. Vaezi MF, Pandolfino JE, Vela MF. ACG clinical guideline: diagnosis and management of achalasia. Am J Gastroenterol 2013;108:1238-49.

3. Moonen AJ, Boeckxstaens GE. Management of achalasia. Gastroenterol Clin North Am 2013;42:45-55.

4. Moonen A, Boeckxstaens G. Finding the right treatment for achalasia treatment: risks, efficacy, complications. Curr Treat Options Gastroenterol 2016;14:420-8.

5. Herbella FA, Aquino JL, Stefani-Nakano S, Artifon EL, Sakai P, Crema E, Andreollo NA, Lopes LR, de Castro Pochini C, Corsi PR, Gagliardi D, Del Grande JC. Treatment of achalasia: lessons learned with Chagas' disease. Dis Esophagus 2008;21:461-7.

6. Marinello FG, Targarona EM, Balagué C, Monés J, Trías M. Surgical treatment of achalasia: Better than dilations? Gastroenterol Hepatol 2009;32:653-61. (in Spanish)

7. Ferreira-Santos R. Tratamento cirúrgico do megaesôfago chagásico. In: Cançado JR (ed) Doença de Chagas, $1^{\circ}$ edição, imprensa oficial do Estado de MG, Belo Horizonte; 1968. p. 592-604. (in Brazil)

8. Panchanatheeswaran K, Parshad R, Rohila J, Saraya A, Makharia GK, Sharma R. Laparoscopic Heller's cardiomyotomy: a viable treatment option for sigmoid oesophagus. Interact Cardiovasc Thorac Surg 2013;16:49-54.

9. Sweet MP, Nipomnick I, Gasper WJ, Bagatelos K, Ostroff JW,
Fisichella PM, Way LW, Patti MG. The outcome of laparoscopic Heller myotomy for achalasia is not influenced by the degree of esophageal dilatation. J Gastrointest Surg 2008;12:159-65.

10. Patti MG, Feo CV, Diener U, Tamburini A, Arcerito M, Safadi B, Way LW. Laparoscopic Heller myotomy relieves dysphagia in achalasia when the esophagus is dilated. Surg Endosc 1999;13:843-7.

11. Crema E, Cruvinel LA, Werneck AM, de Oliveira RM, Silva AA Manometric and radiologic aspects of Chagas' megaesophagus: the importance to its surgical treatment. Rev Soc Bras Med Trop 2003;36:665-9. (in Portuguese)

12. Eckardt VF, Aignherr C, Bernhard G. Predictors of outcome in patients with achalasia treated by pneumatic dilation. Gastroenterology 1992;103:1732-8.

13. Gould D. Information point: visual analogue scale (VAS). Available from: http://www.blackwellpublishing.com/specialarticles/jen_10_706. pdf. [Last accessed on 25 Oct 2017]

14. 36-Item short form survey instrument (SF-36). Available from: https:// www.rand.org/health/surveys_tools/mos/36-item-short-form/surveyinstrument.html. [Last accessed on 25 Oct 2017]

15. Van Hoeij FB, Tack JF, Pandolfino JE, Sternbach JM, Roman S, Smout AJ, Bredenoord AJ. Complications of botulinum toxin injections for treatment of esophageal motility disorders. Dis Esophagus 2017;30:1-5.

16. Arora Z, Thota PN, Sanaka MR. Achalasia: current therapeutic options. Ther Adv Chronic Dis 2017;8:101-8.

17. Vaezi MF, Richter JE. Current therapies for achalasia: comparison and efficacy. J Clin Gastroenterol 1998;27:21-35.

18. Vela MF, Richter JE, Khandwala F, Blackstone EH, Wachsberger D Baker ME, Rice TW. The long-term efficacy of pneumatic dilatation and Heller myotomy for the treatment of achalasia. Clin Gastroenterol Hepatol 2006;4:580-7.

19. Khan AA, Shah SW, Alam A, Butt AK, Shafqat F, Castell DO Massively dilated esophagus in achalasia: response to pneumatic balloon dilation. Am J Gastroenterol 1999;94:2363-6.

20. Ortega JA, Madureri V, Perez L. Endoscopic myotomy in the treatment of achalasia. Gastrointest Endosc 1980;26:8-10

21. Inoue H, Minami H, Kobayashi Y, Sato Y, Kaga M, Suzuki M, Satodate H, Odaka N, Itoh H, Kudo S. Peroral endoscopic myotomy (POEM) for esophageal achalasia. Endoscopy 2010;42:265-71.

22. Inoue $H$, Sato H, Ikeda H, Onimaru M, Sato C, Minami H, Yokomichi H, Kobayashi Y, Grimes KL, Kudo SE. Per-oral endoscopic myotomy: a series of 500 patients. J Am Coll Surg 2015;221:256-64.

23. Akintoye E, Kumar N, Obaitan I, Alayo QA, Thompson CC. Peroral endoscopic myotomy: a meta-analysis. Endoscopy 2016;48:1059-68.

24. Lv L, Liu J, Tan Y, Liu D. Peroral endoscopic full-thickness myotomy for the treatment of sigmoid-type achalasia: outcomes with a minimum follow-up of 12 months. Eur J Gastroenterol Hepatol 2016;28:30-6.

25. $\mathrm{Hu}$ JW, Li QL, Zhou PH, Yao LQ, Xu MD, Zhang YQ, Zhong YS, Chen WF, Ma LL, Qin WZ, Cai MY. Peroral endoscopic myotomy for advanced achalasia with sigmoid-shaped esophagus: long-term outcomes from a prospective, single-center study. Surg Endosc 2015;29:2841-50. 